\title{
Retirement routes and the well-being of retirees
}

\author{
Kadir Atalay ${ }^{1}\left[{ }^{0} \cdot\right.$ Garry Barrett $^{1}$ \\ Received: 10 October 2020 / Accepted: 19 January 2022 / Published online: 17 February 2022 \\ (c) Crown 2022
}

\begin{abstract}
As the Baby-Boomer generation approaches the retirement stage of the life cycle, understanding the implications of the labour market transition for individuals' wellbeing is increasingly important for policy making. In this article, we assess whether individuals successfully navigate the transition from work to retirement by analysing changes in subjective well-being with retirement using Australian panel data. To account for the fact that retirement is often a choice, we exploit social security eligibility rules to identify the causal effect of retirement on well-being. We find that life satisfaction significantly improves for the large majority of individuals who voluntarily retire from the labour force. However, there are also important disparities and individuals forced to retire early do not experience gains in life satisfaction with retirement. Moreover, the negative impact of involuntary retirement is greatest for individuals from disadvantaged backgrounds. We also present new evidence on intra-household retirement spillovers by assessing the effect of one partner's retirement circumstances on their spouse's life satisfaction. The article further extends the literature by examining the mechanisms through which retirement affects individuals' life satisfaction. We find that declines in life satisfaction are in part driven by an increase in financial hardship and reduced social interactions.
\end{abstract}

Keywords Retirement $\cdot$ Life satisfaction $\cdot$ Life cycle $\cdot$ Forced retirement $\cdot$ Pension reform

JEL classification D91 $\cdot$ J26 $\cdot$ J14 $\cdot$ D83 $\cdot$ D84

Kadir Atalay

kadir.atalay@sydney.edu.au

1 University of Sydney, Sydney, Australia 


\section{Introduction}

The demographic transition associated with population ageing is being experienced by many countries around the world, though at varying rates. The Baby-Boomer generation is currently experiencing the late career and retirement stage of the life cycle. As a result, there is heightened research and policy interest in understanding the implications of retirement and labour market withdrawal on elderly individual's well-being.

Economists have begun considering the broad consequences of retirement for wellbeing. A substantial body of the literature has documented that household income and consumption change upon retirement. Individuals' time allocation, social relations as well as physical and mental health are also affected by the transition (Battistin et al. 2009 for consumption; Ciani 2016 for time use; Ardito et al. 2020, Dayaram and McGuire 2019 for health). Conventional methods that assess impact of retirement on well-being compare pre- and post-retirement levels of income, expenditure and consumption (see, for example, Banks et al. 1998) to infer changes in living standards. However, each of these measures face problems arising from the nature of retirement. For example, retirement is a period where income may be tighter but discretionary time more plentiful. Evidence is accumulating that retirees are maintaining their living standards by substituting time for market expenditures. For example, retirees engage more in-home production and spend more time on shopping for lower prices. Thus, retirees may achieve comparable levels of consumption with less market expenditure.

In this article, we examine whether individuals successfully smooth their well-being across the transition to retirement based on measures of subjective well-being (SWB). We use individual's contemporaneous reports of subjective well-being as they make the transition from employment to retirement to evaluate whether they successfully maintain their well-being with this significant life event.

This study contributes to the rapidly expanding economics literature which uses SWB to gauge individual welfare. Our study is in the vein of Easterlin $(2005,29)$ who argues that "the terms well-being, utility, happiness, life satisfaction, and welfare [are] interchangeable." The use of SWB data, which has its own merits and limitations, provides a valuable complement to more traditional welfare concepts based on expenditure, income and wealth. The relationship between SWB and retirement is also studied in recent articles from Europe and USA (see for example Charles 2004; Bonsang and Klein 2012; Kapteyn et al. 2013; Montizaan and Vendrik 2014). These studies generally show that retirement has a positive impact on SWB and there is evidence of heterogeneity in terms of retirement circumstances and gender.

As part of this endeavour, this article provides new evidence on the effect of retirement on well-being using rich contemporary Australian data and accounting for the endogeneity of the retirement decision. This analysis is informative for the development of retirement policy and provides a useful reconciliation of finding from previous studies. We use a longitudinal survey that contains detailed information regarding retirement circumstances. The panel data structure allows us to examine the effect of retirement duration and identify individuals who retire involuntarily. The critical challenge in studying the impact of retirement on well-being is identification of the causal effect. First, retirement is a choice variable and thus there may be reverse causality, such that people with lower levels of well-being might be more likely to retire earlier. 
Secondly, there may be omitted variable and measurement error issues that can cause biased in the estimated effect. In this article, we identify the impact of retirement on well-being by using individual fixed effects and exploiting the eligibility ages at which individuals can access the Age Pension (AP) in Australia. We also explore the mechanisms through which retirement could affect individual's well-being and highlight differences in post-retirement financial hardship and social engagement of voluntary and involuntary retirees.

Our results show that voluntary retirement is associated with significant improvement in SWB for both women and men. Our analysis suggests that in addition to financial changes, individuals' social participation and time allocation are positively associated with their retirement when they voluntarily retire. We find important heterogeneity in the effects of retirement on well-being, especially between voluntary and forced retirement. The negative impact of involuntary retirement is greatest for individuals from disadvantaged backgrounds. Further, we present new evidence on intra-household retirement spillovers by assessing the causal effect of one partner's retirement on their spouse's life satisfaction. We show that involuntary retirement of husbands negatively affects working wives' life satisfaction through a reduction in financial satisfaction.

The structure of the article is as follows. In the following section, the literature on welfare smoothing over retirement and the intersection with SWB measures is briefly reviewed. In Sect. 3 Australian retirement system is described. In Sect. 4, key properties of the data are outlined and descriptive statistics presented. In Sect. 5, the econometrics methods are outlined. Section 6 contains the presentation of the empirical results, and Sect. 7 concludes by drawing out the policy implications of the main findings.

\section{Literature review}

The canonical life cycle model (LCM) of intertemporal consumer behaviour with complete credit markets predicts that an individual's well-being should not be affected by predictable changes in income. An important and substantial change in income occurs at retirement. If retirement is associated with a large anticipated decline in income, the optimal response of an individual is to save in prior periods. The profile of consumption and the trajectory of well-being over the retirement threshold may be considered as a strong test of the simple LCM of individual behaviour.

In assessing the change in individuals' well-being during the transition from employment to retirement, economists have analysed expenditure as a proxy for consumption and well-being. A substantial literature documents a significant fall in expenditures at retirement in many countries and in different time periods; for example, Hamermesh (1984), Banks et al. (1998), Attanasio (1999), Bernheim et al. (2001) and Borella et al. (2014). The widely observed fall of spending at retirement is commonly referred to as the "retirement consumption puzzle". Browning and Crossley (2001) argue that the various changes that individuals experience at retirement contribute directly to decreasing spending, such as the reduction in costs associated with going to work. Retirement is also associated with an increase in time available for 
non-market activities such as home production, which may be a substitute for market expenditures. Aguiar and Hurst (2005) show that individuals are able to smooth consumption at retirement by spending more time searching out bargains and increasing time devoted to food preparation. Aguiar and Hurst find that caloric intake and food quality does not decline at retirement even though a fall in food expenditures is observed due to an increase in home production. Smith (2006) explains the fall in consumption as an unanticipated wealth shock caused by involuntary retirement. Similarly, Barrett and Brazozowski (2012) examined food and grocery expenditures as individuals entered retirement using Australian panel data and found the fall in spending was concentrated among individuals who were forced to retire from work due to long-term job loss or a major health shock.

Given the multitude of changes that occur at retirement, including income and expected future resources, time use and health status, the use of SWB measures has been advocated as providing valuable insights into the welfare of retirees (for example, Alan et al. 2008). The use of these measures is rising in economics as shown by Frey and Stutzer's (2002) detailed survey, and there is support in the literature for the use of SWB as comprehensive measures of welfare (Kahneman and Krueger 2006). Dolan et al. (2008) survey significant SWB correlates reported in the literature, which include income, education, marital status, health and unemployment as well as a range of social capital and community factors.

There is a nascent literature that examines SWB and retirement. Charles (2004) finds a positive correlation between retirement and SWB for men in the USA. Baker et al. (2009) find that income security programs in Canada increase income and decrease poverty among retirees but find mixed effects on reported SWB. Alan et al. (2008) find that most Canadian retirees report enjoying life more in retirement and being at least as satisfied with their finances in retirement, compared to the year prior to their retirement. Involuntary retirement, especially in conjunction with bad health, is found to have a strongest negative affect on life satisfaction. Bender (2004) uses the US Health and Retirement Study to analyse the determinants of overall SWB of retirees and finds involuntary retirement to be the strongest predictor of low well-being. Analysing the same data source, Rohwedder (2006) finds that bad health and deteriorating health have the most significant negative effect on life satisfaction in retirement. For Australia, Zhu and He (2015) examine the life satisfaction of women and find positive impacts of retirement. Zhu and He (2015) consider all Australian women, including women retired at the start of the observation period, and do not distinguish retirement paths. In this article, we consider both men and women at risk of retirement, and hence, we observe individuals making the transition from employment to retirement. Our focus is to distinguish voluntary and involuntary retirement consequences for SWB, which has not previously been studied in Australia. Furthermore, we analyse adaptation of SWB to retirement and the impact of spousal retirement.

There are studies that document heterogeneity in responses to retirement. Bonsang and Klein (2012) examine the causal effect of retirement on domains of life satisfaction using German longitudinal data. They show that involuntary retirement has a negative effect on income satisfaction and consequently on life satisfaction. Hauret and Williams (2017) show that in some countries, females report lower job satisfaction and hence retirement may have differential impacts by gender. Clarke et al. (2012) and 
Falba et al. (2009) show that deviations from expected retirement plans have negative impacts on SWB.

The main concerns in using SWB measures relate to the interpersonal comparability of individual reports and potential biases in survey responses. For example, responses to SWB questions may depend on mood, personality and the specific scale applied in a particular survey. There is also a concern for habituation, whereby the longer an individual experiences a state, such as retirement, the more they adapt to that state and respond with "normal" levels of well-being, implying that long-term shocks to welfare may only have transitory impacts on reported SWB. In analysing measures of reported SWB, Di Tella and MacCulloch (2006) emphasise the value of longitudinal data for individuals as panel data method can allow for individual-specific differences in the origin of the SWB scale. These issues are addressed in our empirical analysis, where we used fixed effects estimators and test for hedonic adaptation.

\section{Institutional background: Australian retirement income system}

Australia's retirement income system has two distinctive features: first is a meanstested, tax financed public pension known as the Age Pension, and the second is a mandatory employer-contributed private saving account known as the Superannuation Guarantee. There is no compulsory retirement age in Australia, and Age Discrimination Act (2004) prohibits discrimination in employment based on age. ${ }^{1}$

The first pillar of the retirement income system, the Age Pension, was introduced in 1909 and is the fundamental safety net for older Australians. As of July 1, 2021, the maximum Age Pension benefit is AUD \$952 (AUD \$1,436) per fortnight per singe (couple). The Age Pension benefit payment is subject to an income and assets test. Eligibility for the Age Pension (APE) is subject to residency and age conditions. Individuals need to have resided in Australia for 10 years prior to application. Prior to July 1995, the qualifying age for women was 60 and 65 for men. From 1995, the eligibility age for women progressively increased by 6 months every two-calendar years, leading to an alignment of APE of 65 years for women and men in 2014. From July 1, 2017, the qualifying age for both women and men increased to 65 years and six months. The qualifying age will continue to increase by six months every two years until reaching 67 years of age in July 2023 (Department of Social Services 2020). The APE ages, which we use to help identify the causal effect of retirement, are summarised in Online Appendix Table 1.

The second pillar, the Superannuation Guarantee, was introduced in 1992 and now requires employers to contribute at least $9.5 \%$ of an employee's pre-tax earnings into a retirement savings account. Upon turning 65, all individuals become entitled to access their superannuation saving even if they are not retired. Otherwise, preservation ages specify the age at which an individual becomes eligible to access their superannuation if they retire before age 65 . As of July 1,2021, the preservation age is 58 for both men and

\footnotetext{
1 There may be indirect mandatory retirement practices. For example, a range of occupations require licensing and re-qualification and such practices may create obstacles for ongoing mature age workforce participation.
} 
Table 1 Distribution of life satisfaction in the analysis sample of HILDA survey

\begin{tabular}{|c|c|c|c|c|}
\hline \multirow[t]{2}{*}{ Life Satisfaction } & \multicolumn{2}{|l|}{ Female } & \multicolumn{2}{|l|}{ Male } \\
\hline & Count & $\%$ & Count & $\%$ \\
\hline 0 & 23 & 0.11 & 13 & 0.05 \\
\hline 1 & 29 & 0.12 & 32 & 0.12 \\
\hline 2 & 70 & 0.3 & 62 & 0.24 \\
\hline 3 & 139 & 0.6 & 131 & 0.5 \\
\hline 4 & 205 & 0.87 & 237 & 0.9 \\
\hline 5 & 743 & 3.18 & 779 & 2.97 \\
\hline 6 & 1141 & 4.87 & 1380 & 5.26 \\
\hline 7 & 3947 & 16.83 & 5103 & 19.45 \\
\hline 8 & 8124 & 34.65 & 9517 & 36.27 \\
\hline 9 & 6213 & 26.46 & 6213 & 23.68 \\
\hline 10 & 2792 & 12 & 2774 & 10.57 \\
\hline Total & 23426 & 100.00 & 26241 & 100.00 \\
\hline
\end{tabular}

women. ${ }^{2}$ The third pillar of the retirement income system is voluntary savings which includes private savings and additional personal contributions to superannuation.

The Age Pension is the main source of income for retired Australians. Approximately $70 \%$ of the retirement-age population receive the Age Pension and approximately two-thirds of this population receive the full pension amount, highlighting the importance of the Age Pension for Australian retirees. Eligibility for the Age Pension therefore creates a significant incentive for Australians to retire. Our empirical strategy exploits the exogenous retirement incentives generated by Age Pension eligibility. ${ }^{3}$

\section{Data and sample construction}

The empirical analysis is based on data from the Household, Income and Labour Dynamics in Australia (HILDA) Survey. This panel study tracks approximately 10,000 Australian households, comprising of more than 17,000 individuals, through time with the first wave collected in 2001. The analysis is based on a sample of individuals aged between 50 and 75 observed during the waves one to nineteen (years 20012019). The sample is restricted to those who were first observed to be employed and hence represent the set of individuals "at risk" of retirement. We drop individuals who return to work during the sampling period. ${ }^{4}$ This provides a sample of 49,667 person-year observations, based on 6,296 individuals. During the observation period

\footnotetext{
2 In limited circumstances, for example, when individuals require funds to accommodate a disability, access to superannuation may be granted prior to reaching the preservation age.

${ }^{3}$ In Sect. 4, we provide evidence how age pension eligibility affects the average retirement rates (see Fig. 2).

${ }^{4}$ Our results are robust to inclusion of individuals who return to the workforce.
} 
1,717 individuals are observed to make the transition to retirement. The sample is an unbalanced panel as not every individual meets the sampling rule, or is present, for every wave of the survey.

The key SWB measure used as the dependent variable in the main analysis is selfreported life satisfaction. The question asked during a personal interview conducted for each annual wave is: "All things considered, how satisfied are you with your life?" Possible responses on an eleven-point scale range from 0 (totally dissatisfied) to 10 (totally satisfied). Table 1 presents the distribution of life satisfaction responses for the full analysis sample, as well as the separate samples of men and women. As is typical of SWB data, the responses are concentrated toward the top of the scale. The modal response for the combined sample is 8 , which is also the modal response for the separate samples by gender. The standard deviation of life satisfaction responses for the female subsample is 1.39 ( 0.85 within individuals) and 1.33 ( 0.82 within individuals) for the male subsample.

The objective of the analysis is to examine how life satisfaction changes due to retirement. We define as retired individuals who self-report their current labour market status as not in the labour force. For robustness checks, we use an alternative definition of retirement and identify retirement from people's responses to the life events module ("did any of these happen to you in the past 12 months?") which is part of HILDA's self-completion questionnaire in every wave except wave 1 . The results using this definition are very similar to our main results. The measured effect of retirement is based on changes in contemporaneous changes in reports of SWB with the transition to retirement, rather than retrospective recall of a prior transition. That is, the analysis will be based on within-person variation in SWB and labour force status. The indicator of whether retirement was forced or "involuntary" is directly self-reported by retirees. To identify involuntary retirees, we use a question that is asked in the special retirement modules in wave three (2003), seven (2007), eleven (2011), fifteen (2015) and nineteen (2019). The precise question is "Thinking back to the time you retired, was that something you wanted to do or something you felt you were forced or pressured to do?". We classify individuals as involuntarily retired if they report that they were "forced or pressured" to retire. Years spent in retirement is constructed based on the longitudinal structure of the survey and used to assess evidence of habituation in the effect of retirement on SWB. Additional explanatory variables used in the analysis include the individual's age, educational attainment, social marital status (single, partnered or separated/divorced/widowed), an indicator of whether dependent children are present, housing tenure (renter, outright homeowner, homeowner with a mortgage) and location (state of residence). The data also contain self-reported health status and long-term health conditions.

Descriptive statistics for the samples are presented in Table 2. For the female sample, the average age of an individual during the sample period was 58.6 years, with 23 percent of observations from recorded when retired. Of the 2,943 individuals forming the female sample, 883 females are observed to make the transition to retirement by 2019. Approximately 7 percent of retired observations corresponds to forced retirement. As detailed below, eligibility age for the Age Pension is used as an instrumental variable to identify the effect of retirement on SWB. Approximately one-fifth of the observations are for individuals who meet the Age Pension eligibility age and average 


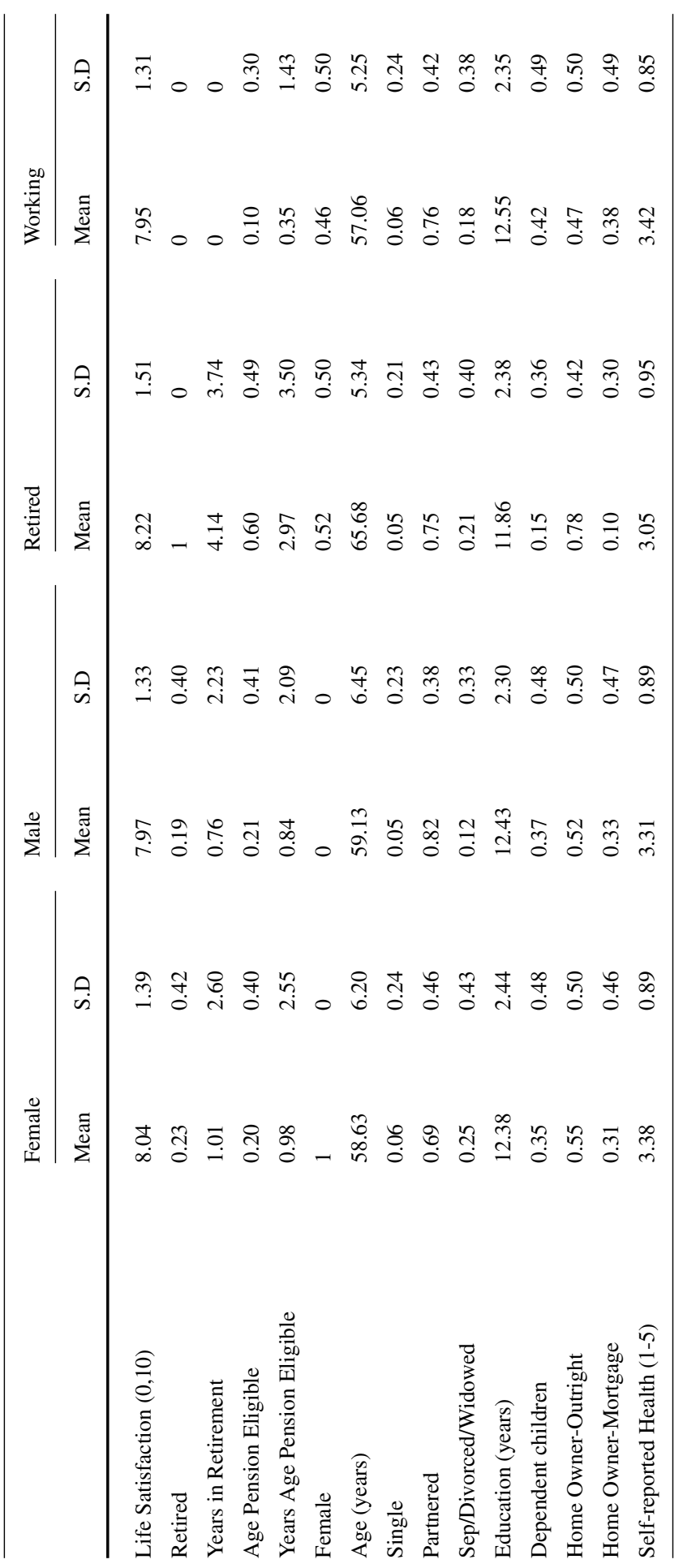




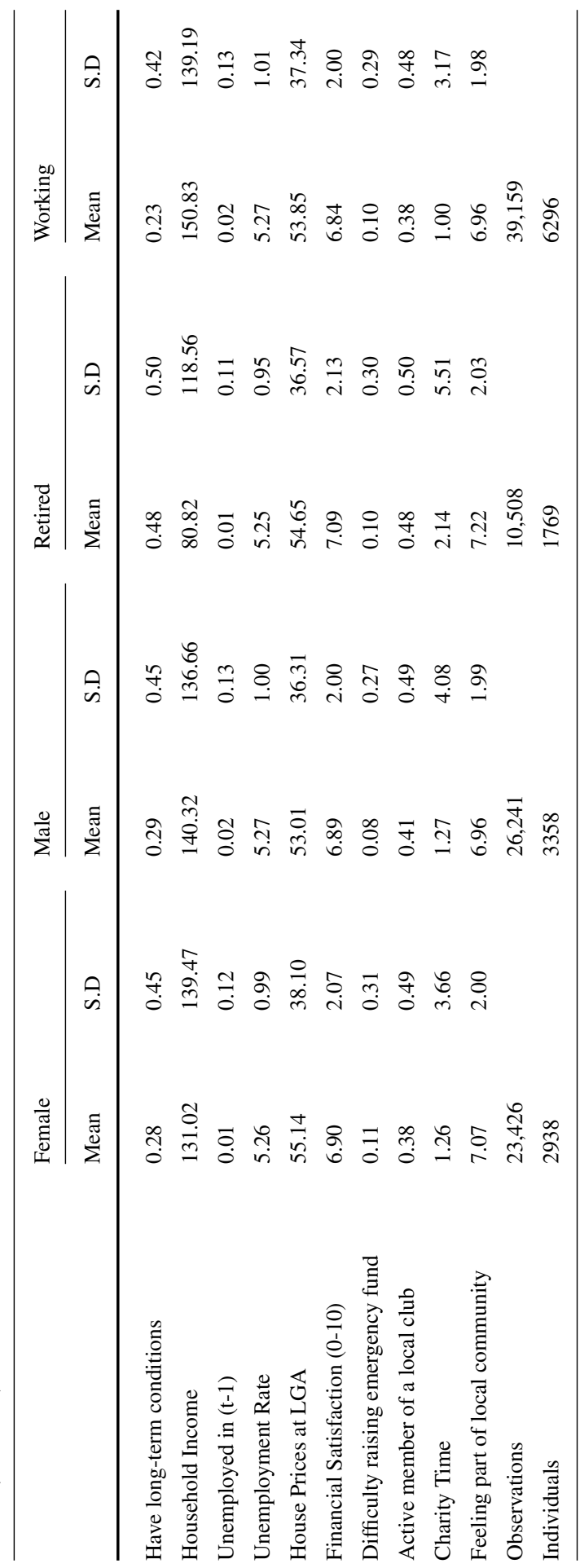


duration of eligibility is around 1 year. The majority of observations are for partnered individuals, who have no dependent children present and are homeowners. The sample for males has a marginally lower incidence of retirement and shorter duration in retirement, higher incidence of being partnered and a lower incidence of being separated, divorced or widowed compared to the sample for females. Comparing the sample means by retirement status, retirees have a higher reported life satisfaction, higher mean age, lower education and a higher incidence of outright home ownership compared to the sample for workers.

The longitudinal dimension of the survey allows us to observe the evolution of SWB around the time of retirement. Figure 1 presents average SWB in the five years before and the five years after retirement. In the figure, year 0 represents the first year in which the individual is retired. Panels $\mathrm{A}$ and $\mathrm{C}$ of the figure illustrate that voluntary retirement increases SWB for both men and women. The panels B and D show a different trend where a decline in SWB is observed when the individual involuntarily retires from the labour force. It is important to note that these graphs provide descriptive evidence on the cross-sectional variation in the data and do not control potential confounders such as age, income of individuals and year effects. Controlling for such factors is necessary in order to disentangle the influence of retirement on SWB.
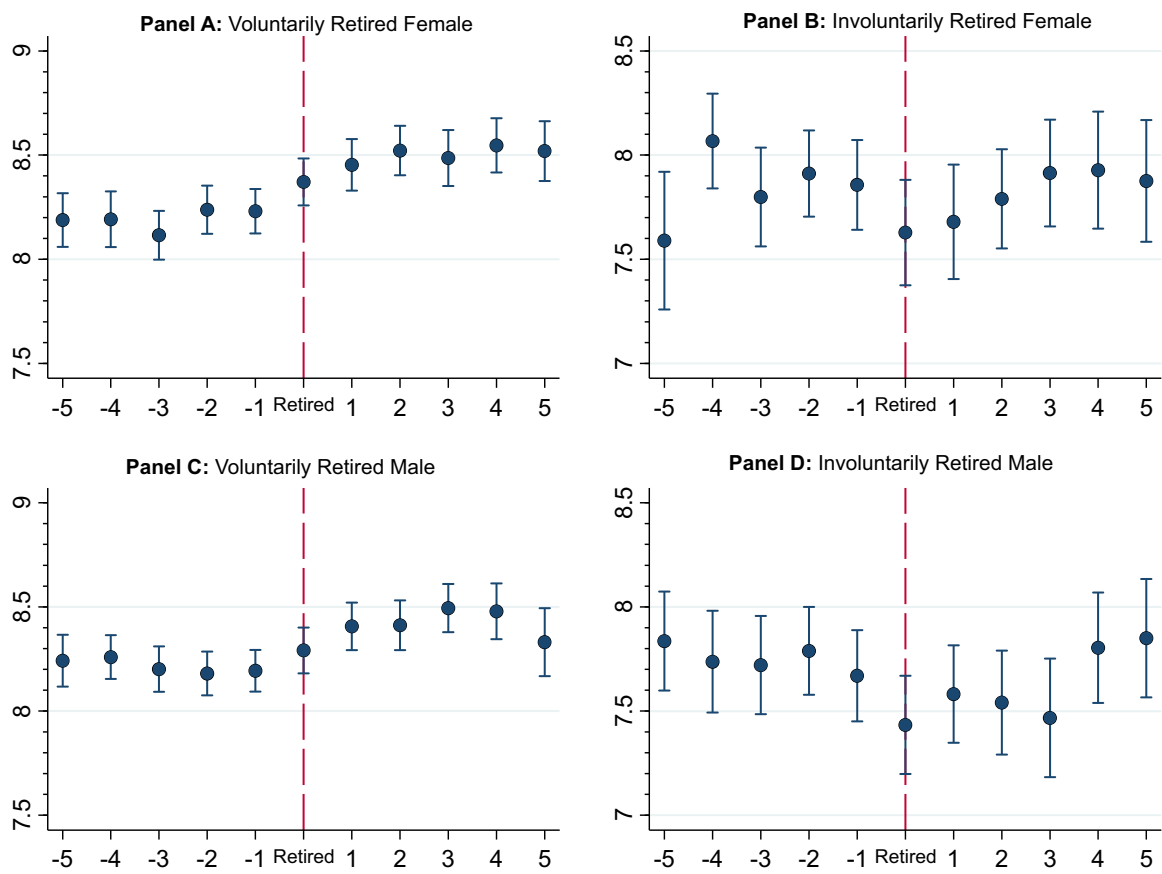

Fig. 1 Life satisfaction and retirement 


\section{Methods}

\subsection{Fixed effects estimator}

The empirical analysis of the effect of retirement on SWB is based on the fixed effects regression model with the specification given by:

$$
S W B_{i t}=\delta_{1} \text { Retired }_{i t}+x_{i t}^{\prime} \beta+\alpha_{i}+\gamma_{t}+e_{i t} \quad i=1, \ldots, N ; \quad t=1, \ldots, T
$$

where $x_{i t}$ are observed explanatory variables, $\alpha_{\mathrm{i}}$ is an individual-specific effect, $\gamma_{t}$ capture common time-period specific effects, and $e_{i t}$ is an idiosyncratic error term assumed to be independent of $x_{i t}, \gamma_{t}$ and $\alpha_{\mathrm{i}}$. The characteristics composing $x_{i t}$ include the person's age, sex, social marital status, state of residence, the presence of dependent children, health status and disability status. ${ }^{5}$ The fixed effects regression model is chosen because it does not place restrictive distributional assumptions on the unobserved individual effect. The fixed effects estimator is identified by within-person variation in covariates over time. Inclusion of the individual fixed effect $\alpha_{i}$ permits individual differences in the origin of the life satisfaction scale. In this specification, the coefficient on the Retired it $_{\text {indicator, }} \delta_{1}$, measures the average within-person difference between life satisfaction in employment and in retirement, conditional on the other observed covariates. SWB is an ordinal variable measured on 0-10 scale. As is common in the literature, all specifications use ordinary least squares (OLS) individual fixed effects as the ordinality of the data has little consequence for the estimation result (Ferrer-i-Carbonell and Frijters 2004). The model specification is then augmented with

$$
\begin{gathered}
S W B_{i t}=\delta_{1} \text { Retired }_{i t}+\delta_{2} \text { Forced }_{i t}+x_{i t}^{\prime} \beta+\alpha_{i}+\gamma_{t}+e_{i t} \quad i=1, \ldots, N \\
t=1, \ldots, T
\end{gathered}
$$

The inclusion of the Forced indicator allows for the decomposition of the retirement effect into voluntary and involuntary components. As considered in the literature on the retirement-consumption puzzle, the coefficient on the forced retirement indicator can be interpreted as the impact of an unanticipated negative wealth shock at the time of retirement.

\subsection{Fixed effects instrumental variable estimator}

The FE estimator for (1) and (2) will capture the causal effect of retirement on SWB if the retirement indicator and other observed covariates are uncorrelated with the idiosyncratic error term $e_{i t}$. However, if there are time-varying components of the error term $e_{i t}$ correlated with Retired status, the estimator will be inconsistent. To address this possibility, a fixed effects instrumental variable estimator will also be

\footnotetext{
5 Our results are robust to including household current income.
} 
implemented. The model specification for this estimator is:

$$
\begin{aligned}
& S W B_{i t}=\delta_{1} \widehat{\text { Retired }}_{i t}+x^{\prime i t} \beta+\alpha_{i}+\gamma_{t}+e_{i t} \\
& \text { Retired }_{i t}=x_{i t}^{\prime} \gamma+z_{i t} \eta+\mu_{i}+\kappa_{t}+u_{i t} \quad i=1, \ldots, N ; \quad t=1, \ldots, T
\end{aligned}
$$

Similar to Bonsang et al. (2012) who use pension eligibility ages as an instrumental variable for retirement status, we create indicators for age thresholds at which economic incentives to retire increase substantially. In this set-up, the discontinuities act as instruments for individuals' employment status in a FE-IV model, with age as the variable determining the discontinuities. The identification relies on the assumption that SWB should be a continuous function of age conditional on work status (Angrist and Piscke 2009; Imbens and Wooldridge 2009). This idea is similar to the regression discontinuity design (RDD) estimator. However, our model focuses on the variation within individuals across time by including individual fixed effects. ${ }^{6}$ Eligibility ages for the Australian Age Pension program are displayed in Online Appendix Table 1 . While reaching these specific ages has a direct effect on the probability of retirement, it is unlikely that the effect of age on SWB is discontinuous at these (or other) ages, keeping labour force status constant. Formally the instrument is defined as $z_{i t}=I\left(A g e_{i t}^{c} \geq\right.$ Pension $\left.A g e_{i}^{c}\right)$, where $\mathrm{I}($.$) is the indicator function that takes a$ value of one if the individual's age is equal to or greater than the qualifying age for the pension. The duration of Age Pension eligibility (Max[0, agecit-Pension Ageci]) is constructed as an additional instrumental variable for analysing the effect of time spent in retirement on SWB to test for potential hedonic adaptation.

Given the panel data framework, there are two sources of variation in the instrumental variable. The primary source of variation is longitudinal, corresponding to individuals ageing during the observation period and crossing the relevant age pension eligibility threshold. A secondary source of variation is cross-sectional and is due to differing age pension eligibility thresholds applying to different birth cohorts. This cross-sectional variation is most relevant and substantial for the female sample given the reform to APE for women introduced in 1995. ${ }^{7}$ The later APE reform of 2017 applied to both men and women. However, the major source of variation is longitudinal which relies on discontinuities associated with an individual crossing the APE threshold, conditional on a smooth age profile of SWB and other observed factors. Figure 2 shows age specific retirement rates by pension eligibility from our data. For females, in the age group 61.5 to 65 years, we distinguish between individuals who are eligible and not eligible for the Age Pension, and it clearly shows the jump in retirement rates with eligibility. For males, we observe the jump at the single eligibility threshold of 65 years.

\footnotetext{
6 The fixed effects also control for the expected social security wealth of individuals.

7 The Age Pension reforms summarised in Online Appendix Table 1 represent a significant negative wealth shock for women in the targeted birth cohorts as there is no accrual of higher benefits from delayed retirement. Atalay and Barrett (2015) show that this program reform has a significant impact in delaying women's retirement over ages 60-65 years for women directly targeted by the reform and represents a powerful instrumental variable for identifying the causal impact of retirement for women.
} 

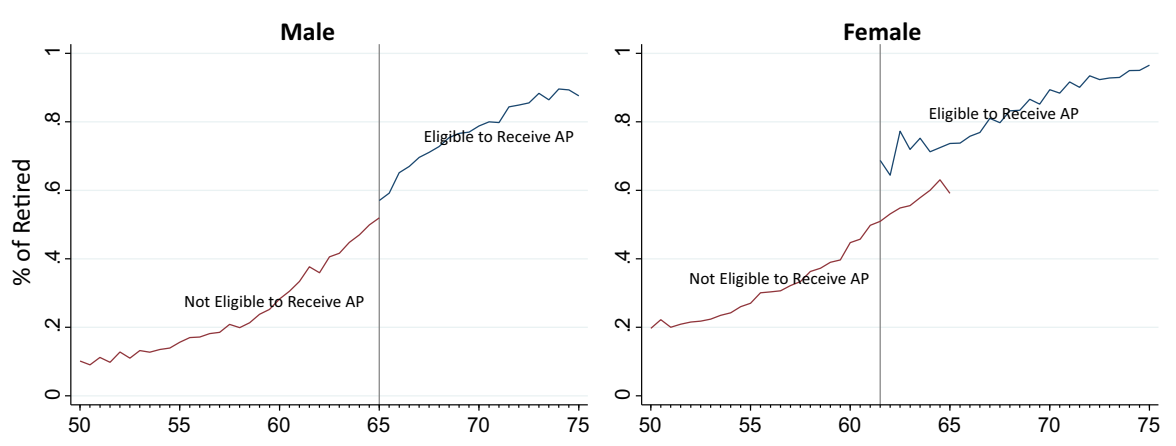

Fig. 2 Retirement rates by age

The IV estimator of $\delta_{1}$ represents a local average treatment effect (LATE) of retirement on SWB. Hence, the coefficient measures the mean impact of retirement on life satisfaction for individuals who are "compliers" and delay their retirement to reach the APE they face, conditional on observed covariates. This LATE, which isolates variation in retirement status induced by the social security reform, is policy relevant and corresponds to a voluntary change in retirement decision. We do not have a credible instrumental variable for forced retirement, and therefore, the forced retirement indicator is not included in the model.

\section{Empirical results}

\subsection{Fixed effects results}

Table 3 reports the results of panel regression estimates of the conditional mean effect of retirement on SWB based on model (1). The first three columns report the estimates for the male sample and next three for the female sample. For the male group result in column (1), retirement is found to have an insignificant impact on life satisfaction, holding other observed factors constant. For females (column (4)), the impact of retirement is positive and statistically significant, though the magnitude is small at 0.076 given the $0-10$ scale of SWB. In terms of other covariate effects, age is found to have an insignificant quadratic relationship with life satisfaction, which is in part due to the limited age range examined in this study. Relative to the reference category of single, partnered individuals report substantially higher SWB. Having dependent children in the household is associated with lower SWB, other things equal. Home ownership and especially outright ownership, in comparison with mortgagees, experience greater SWB relative to renters, other factors equal. This latter effect may reflect the positive influence of wealth on SWB, and it may also reflect greater financial and housing security associated with home ownership. As expected, general health positively, while having a disability negatively, impacts SWB.

The literature on the retirement-consumption puzzle highlighted the importance of the reasons for retirement on the level of consumption and welfare experienced in 


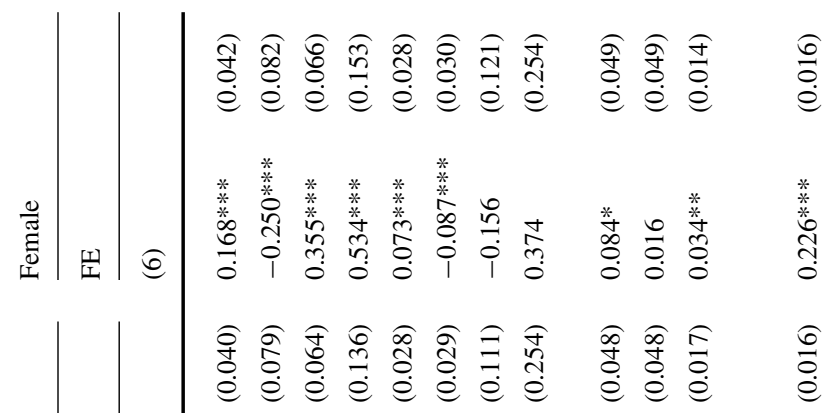

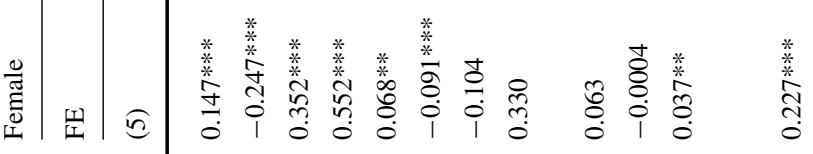

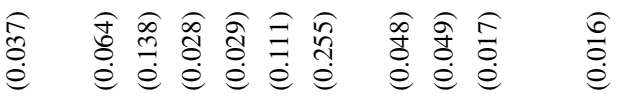

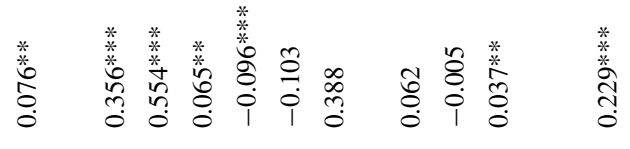

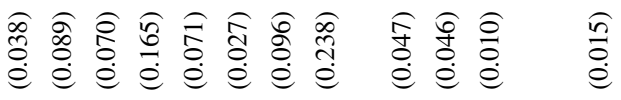

$\stackrel{\mathscr{E}}{\exists}$

1

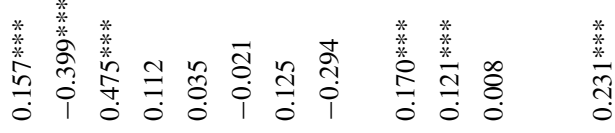

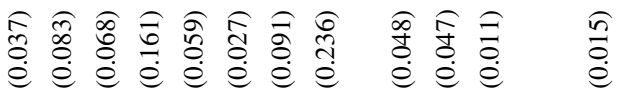

苛

造 $\widehat{\frac{\pi}{\Sigma}}$

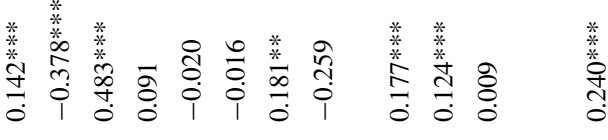

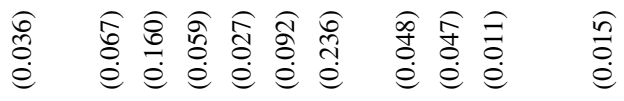

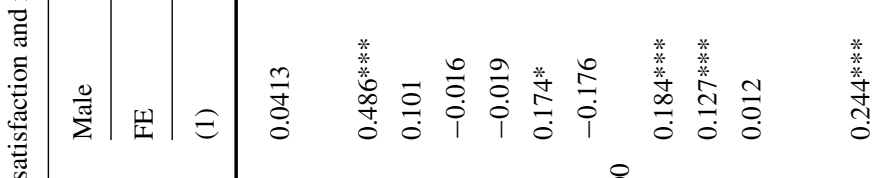

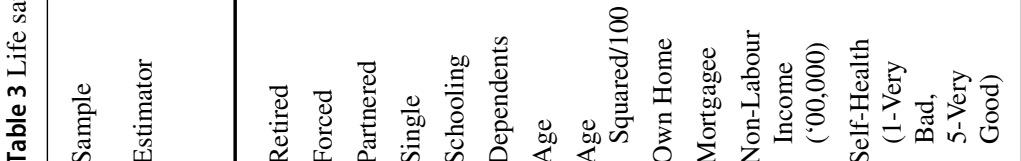

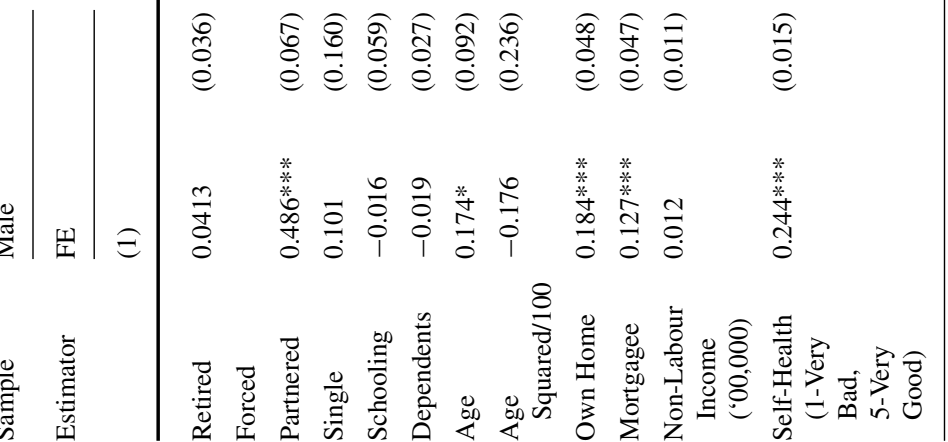




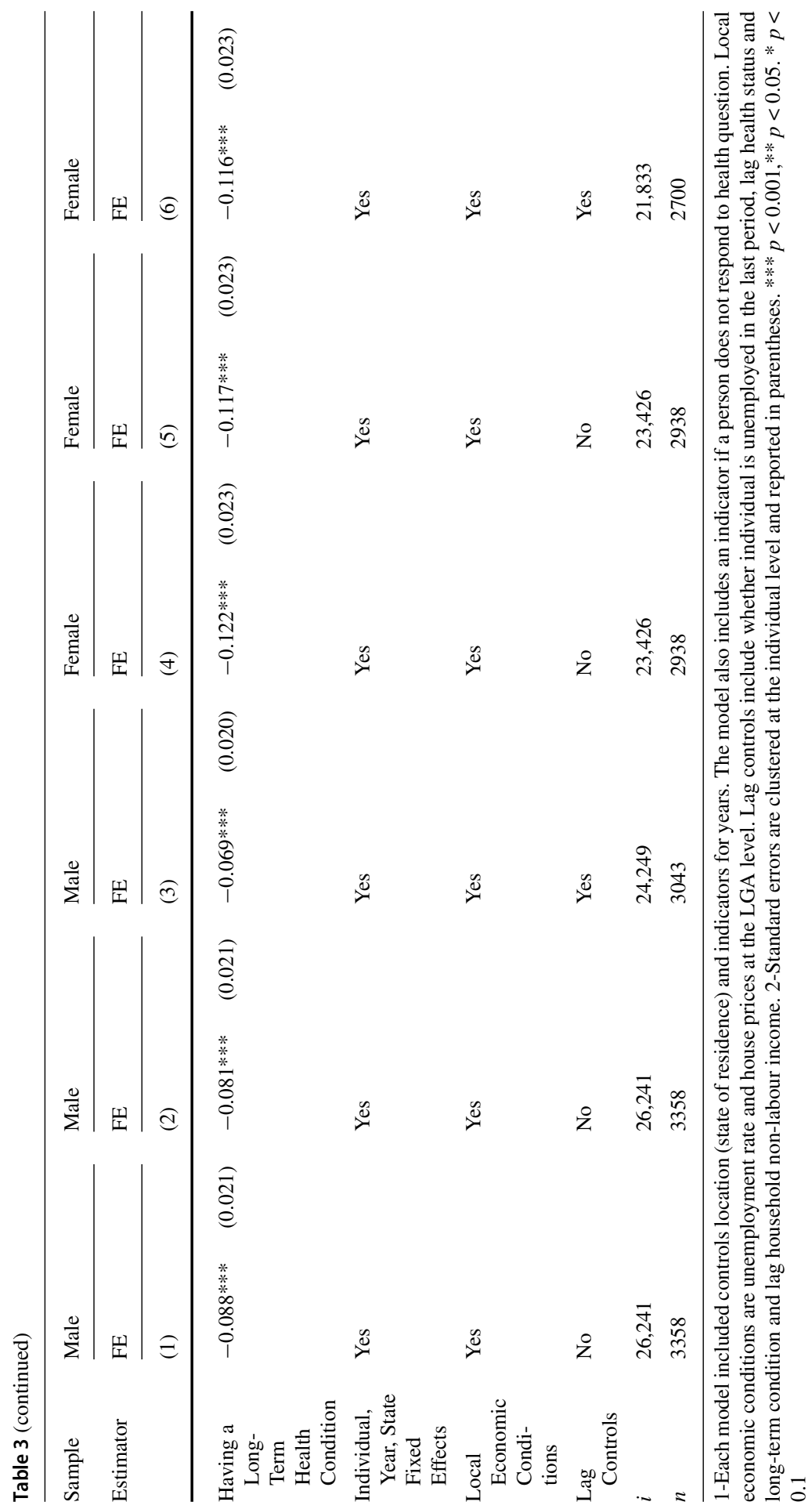


retirement. In particular, in line with the LCM of intertemporal choice, individuals who are forced to retire such as due to a major health event are likely to find retirement to be associated with a lower level of well-being than that experienced during the prior period of employment. The model specification was augmented to include the indicator for whether retirement was forced; the base category is voluntary retirement. With this additional control variable, the coefficient on the retirement indicator is now larger. In column 2, the coefficient on forced retirement for males is negative, large in magnitude and statistically significant. The estimated net effect of retirement for males who retire involuntarily $\left(\hat{\delta}_{1}+\hat{\delta}_{2}=0.142-0.378=-0.236\right)$ is significantly negative but small in magnitude. Column 6 shows that for females, voluntary retirement has the significant positive impact on SWB, while the net effect of forced retirement is negative but statistically insignificant $(-0.10, p$-value $=0.16)$. Together, the results from this model imply that voluntary retirement is associated with a gain in SWB as individuals transition out of the labour force. However, individuals that do not retire according to their plans but are forced to retired unexpectedly earlier do not experience the gain in SWB with retirement. On average, these individuals report no appreciable change in life satisfaction with retirement, conditional on the other observed factors. It is possible that some individuals planned to work into the future experienced a negative health or labour market shock, thought did not retire contemporaneously with the shock but continued to remain in the labour force for an additional year before retiring. To check for this possibility, in columns (3) and (6) we include lagged unemployment and disability status in the set of control variables. These additional covariates lead to a slight decrease the magnitude of the estimated forced retirement effect, but the coefficients are not statistically significantly different from those reported in columns (2) and (6).

\subsection{Fixed effects instrumental variable results}

The results based on the FE regression model may not reflect the causal effect of retirement on SWB if there are time-varying latent factors which influence SWB and are correlated with retirement status. These factors may reflect aspects of individual health, cognitive functioning or perhaps dimensions of social capital. To address this possibility, an instrumental variable approach to identifying the causal effect of retirement on well-being was pursued. The FE-IV panel estimator captures a local average treatment effect (LATE), the causal effect of retirement on SWB for the set of individuals who change their retirement decision due to reaching eligibility age. This represents a policy-relevant treatment effect of voluntary retirement on individual SWB in that this group of compliers is, by definition, making a behavioural response to the policy lever.

First, we examine the first-stage regression results from FE-IV estimations. The results reported in the first two columns of Table 4 help assess whether the instrumental variable we use satisfies the relevance condition for a valid instrumental variable. The coefficient estimates of the age eligibility variable are highly significant for each gender sample, indicating that age eligibility for the Age Pension is a strong predictor 


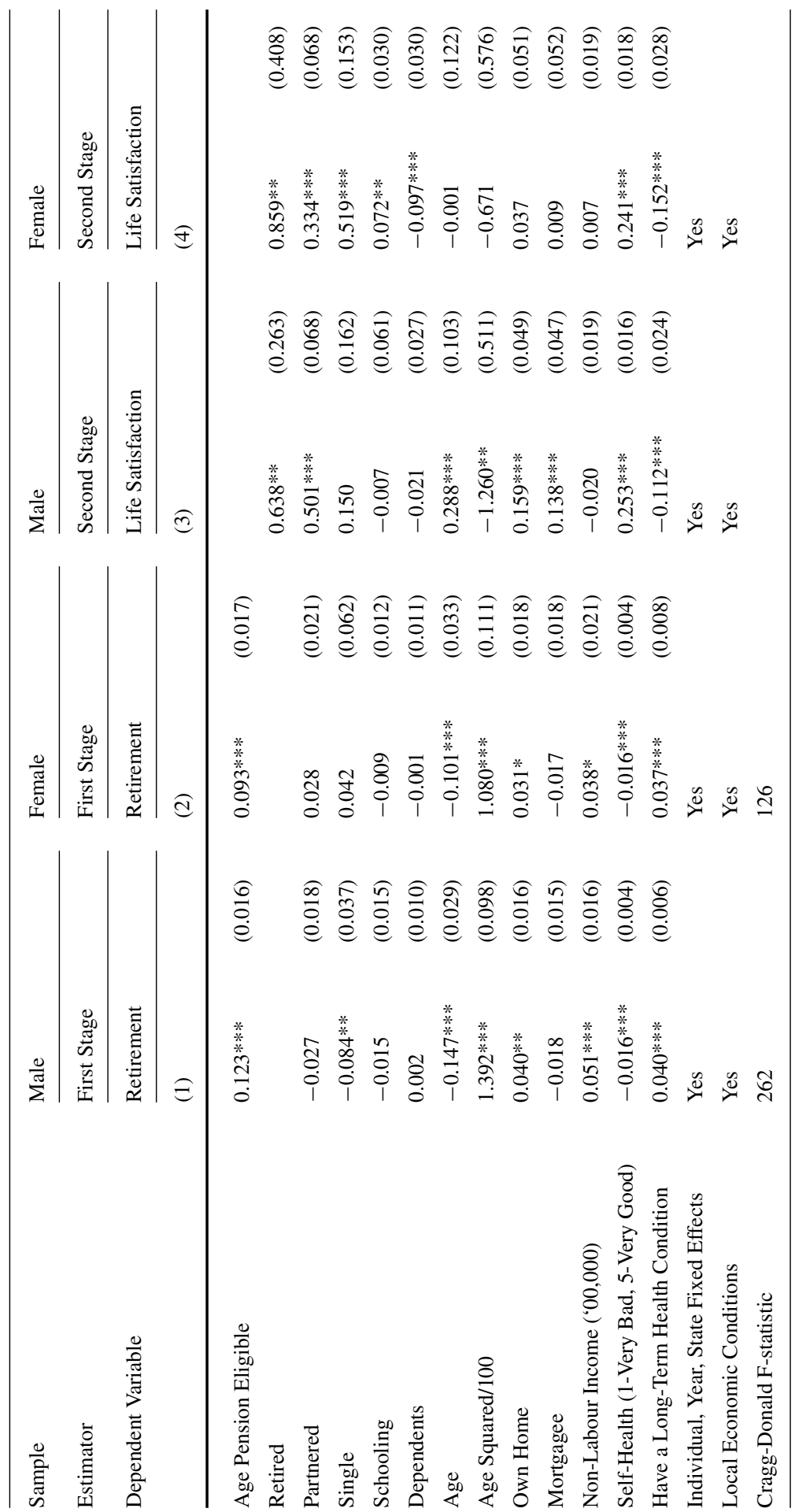




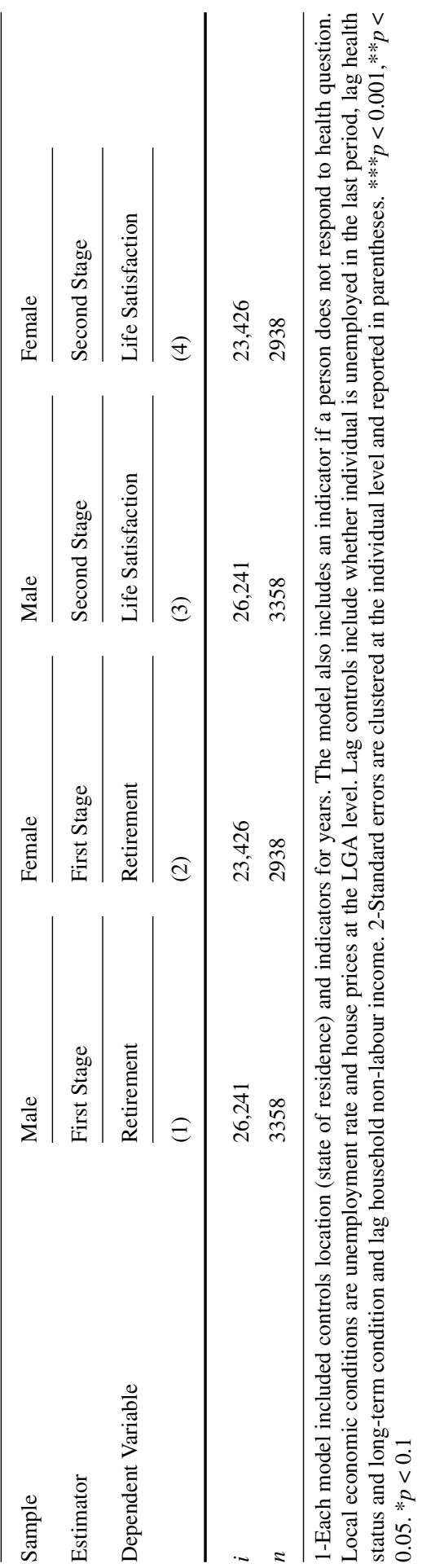


of retirement behaviour in Australia. For females, being over the Age Pension eligibility age increases the probability of being retired by 9.3 percentage points and the retirement-inducing effect is 12 percentage points for males. The first-stage F-statistics on the excluded instrument far exceed the Stock and Yogo (2005) rule-of-thumb threshold of 16, indicating that the instrument is not weak and has sufficient explanatory power in our specifications.

Columns (3) and (4) of Table 4 present the result based on the FE-IV estimator for males and females, respectively. For both groups, retirement is estimated to have a significant and a large positive impact on SWB, with the coefficient estimate close to 0.6 for men and 0.8 for women on the $0-10$ scale. These effects are approximately half a standard deviation (for men 0.47 and for women 0.57 ). This is a modest though economically important impact of retirement on individual well-being. The results imply that individuals who retired voluntarily and time their retirement to coincide with their pension access successfully smooth their well-being over the employmentretirement phase of their life cycle and in fact experience a substantial welfare gain. For females, the estimated causal effect is significantly larger than that found based on the FE estimator reported in column (6) of Table 2. This larger estimated effect of retirement may be due to (a) the FE estimates being affected by unobserved timevarying individual factors confounding the effect of retirement on SWB, or (b) the FEIV causal effects being "local" to the set of females who are able revise their retirement in light of the updated APE to access social security benefits. This set of women may have lower levels of lifetime wealth or are liquidity constrained, consequently are more responsive to the APE change and therefore delay their exit from the labour force due to the later qualifying date. For this subset of women, retirement (and subsequent receipt of Age Pension payments) represents a substantial welfare improvement in well-being. To further explore this, we estimate the mean of each characteristic for compliers using the weighing scheme suggested by Abadie (2003) and Marbach and Hangartner (2020) and compare with the population average. Overall, compliers appear to be healthier, more likely to be partnered and have university degree. At the same time, they have lower income, they are more likely to be renters and they live in less prosperous neighbourhoods as compared to the average. We also observe that the incidence of the involuntary retirement for compliers is negligible.

\subsection{Heterogeneous Effects}

The literature on the retirement-consumption puzzle shows that the decline in expenditures were greatest for households with lowest amount of resources and more at risk of experiencing negative wealth shocks (Bernheim et al., 2001). In line with this idea, in Table 5 we examine potential heterogeneity in the estimated effects on SWB across subgroup. In panel A, we examine the retirement effects by splitting the sample into blue- and white-collar occupational groups defined according to an individual's occupation when first observed in the sample. (By construction, all individuals are 
Table 5 Heterogeneity across sub-groups

(1)

\section{Panel A-Occupation Groups}

Panel A

Blue Collar

Male

Retired

0.0387

(0.0703)

Forced

$-0.425^{* * * *}$

(0.127)

$N$

8366

1205

(2)

(3)

(4)

\section{Panel B-education groups}

\section{Panel B}

Low education

Male

Retired

0.100

(0.0730)

Forced

$-0.467 * * *$

(0.140)

$N$

8224

1105

\section{Female}

0.0616

(0.0642)

$-0.270 * *$

(0.114)

9680

1199

Panel C-distribution of life satisfaction

\section{Quantile fixed effect estimation}

Panel C

Male

Q25th

Retired

$0.119 * *$

(0.059)

$-0 . .419 * * *$

(0.122)

Female

Q25th

Retired

$0.135 * * *$

Forced
Median

0.144

(0.179)

$-0.373$

(0.369)

Median

$0.149 * * *$

(0.048)

$-0.243$

(0.090)

$$
\text { (0.050) }
$$

$-0.273 * * *$
White Collar

Male Female

$0.198 * * *$

$0.173 * * *$

(0.0433)

(0.0423)

$-0.304 * * *$

$-0.210 * *$

(0.111)

(0.0862)

13,697

16,776

1824

2269

High education

Male Female

$0.158 * * *$

$0.219 * * *$

(0.0426)

(0.0513)

$-0.273^{* * *}$

$-0.247 * *$

(0.0979)

(0.104)

18,017

13,746

2294

1839

(0.0936)

1-Panels $\mathrm{A}$ and $\mathrm{B}$ use Eq. 2 (fixed effect regression). We utilise a quantile fixed effect model for panel C. 2-Each model included full controls listed in Table 3 and controls location (state of residence) and indicators for years. 3- $* * * p<0.001, * * p<0.05$. * $p<0.1$ 
employed when they first appear in our sample.) In panel B, we look at the effects when dividing the sample into two educational groups; the "low education" group corresponding to individuals who completed high school or less and "high education" corresponding to those with post-secondary or high degree qualifications. These groups represent individuals with differing labour market opportunities and expected lifetime resources. Columns (1) and (2) show the impact of retirement on SWB for individuals for blue-collar worker, and less than post-secondary qualification. For both males and females, we observe small and insignificant effects of voluntary retirement and highly significant large negative effects of involuntary retirement. For white-collar and more highly educated people (columns (3) and (4)), we observe large positive impacts of voluntary retirement on SWB.

We also examine whether the effects of retirement differ for men and women according to their accumulated household wealth. Due to potential endogeneity of wealth, these results are not reported, but they are in line with findings of panel A and B: positive benefits of retirement are associated with the top segments of the wealth distribution and negative of involuntary retirement concentrated at the bottom wealth of the distribution. This pattern indicates the transition in retirement increases the wellbeing of individuals that have adequate resources, while individuals with low wealth experience substantial declines in SWB when they involuntarily retire.

In panel $\mathrm{C}$ of Table 5, we examine heterogeneity in the effects of voluntary and involuntary retirement at different points of the distribution of SWB. For this analysis, we use the panel data quantile regression model with fixed effects as recently developed by Machado and Silva (2019). Columns (1), (2) and (3) of panel C report the FEQuantile estimation results at the 25th, median, 75th percentiles of the conditional distributions of subjective well-being. The median estimates are very close to the mean estimates reported in Table 3. However, the negative effect of involuntary retirement has larger impacts at the lower tail of the conditional distribution of SWB. These results suggest that voluntary retirement more strongly benefits the most satisfied individuals, while involuntary retirement is more detrimental to least satisfied, other things equal.

\subsection{Hedonic Adaptation}

The issue of hedonic adaptation or habituation to retirement was then examined. Using the longitudinal structure of the HILDA Survey, the duration of time retired was constructed for individuals observed making the transition to retirement. The FE panel regression models were re-estimated with the inclusion of the time spent retired. For the FE-IV estimator, an additional instrumental variable was constructed corresponding to the duration of Age Pension eligibility.

The model estimates are presented in Table 6. Columns (1) and (2) present estimates based on the FE estimator for the male sample. In column (1) which controls for retirement but not forced retirement, the inclusion of time spent retired leads to a slight change in SWB at the time of retirement (compared to column (1) in Table 4), while an additional year spent retired is found to have no effect on SWB. Column (2) extends the base specification by including an indicator for forced retirement and an interaction between forced retirement and duration of time spent in retirement. This 


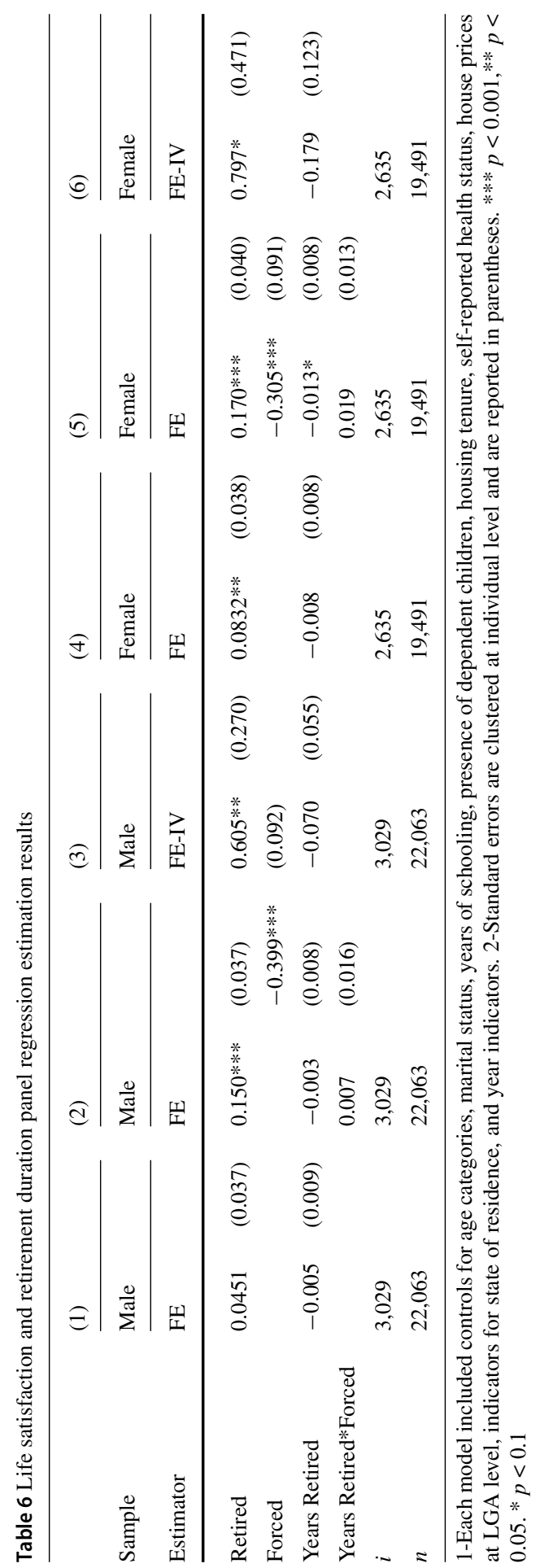


specification permits potential hedonic adaptation paths to vary for those voluntarily retired and those forced to retire. The estimates imply that voluntary retirement has an initial positive impact on SWB followed by an insignificant change with the duration of time in retirement. This implies that men who voluntarily retire do experience a significant gain in SWB at the time of retirement, and over time that gain is not lost. For females in column (5), we observe a slightly different trend as the estimates imply that voluntary retirement has an initial positive effect on SWB followed by a negative impact of retirement duration in SWB. This may be due to a "honeymoon" effect whereby individuals are initially positively surprised by the experience of retirement which then recedes over time. Alternatively, the time profile of SWB is consistent with partial hedonic adaptation to retirement. The estimates imply that it takes on average 13 years in retirement for SWB to return to the pre-retirement baseline, which is at the extreme of the observed sample values of retirement duration. However, individuals who involuntarily retire do experience some loss in SWB at the time of retirement and over time that loss dissipates; however, this effect is not significant. Using the eligibility ages for AP and AP eligibility duration, the FE-IV estimates for the male and female sample are presented in columns (3) and (6). In this specification, the gain in SWB with retirement is similar than that reported for the FE-IV specification in Table 4. For both genders, the duration of retirement is insignificant though the point estimates are in line with findings in previous columns. The robustness of these results for hedonic adaptation were also examined. Alternative specifications for the inclusion of time spent in retirement were considered, including use of polynomials as well as step functions and linear splines, for time spent in retirement. The finding from these alternative specifications was consistent with the pattern of findings presented in Table 6.

\subsection{Potential Mechanisms}

The next step in the analysis was to explore the mechanisms through which retirement may affect individual's SWB. Retirement is often accompanied by a decrease in income and market expenditures (Bernheim et al. 2001) which may alter individual's financial circumstances. At the same time, leaving employment alters the lifestyle of individuals, inducing changes in physical activity and social interaction which consequently may impact well-being. Negative financial and social impacts may be pronounced for involuntary retirees; on the other hand, voluntary retirees may have anticipated and prepared for these changes and might be positively impacted. To examine the potential mechanisms that could drive the association between retirement circumstances and SWB, we use the same estimation strategy described in Eq. (2), based on the fixed effects regression estimator, and consider financial circumstances and social engagement. In particular, we focus on information regarding (i) individuals' financial satisfaction (rated 0-10), (ii) financial prosperity (rated 0-6), (iii) whether an individual is able to raise emergency funds, (iv) whether the individual feels part of a local community (rated 0-10), (v) time spent doing voluntary work and (vi) whether the individual is an active member of a club. 


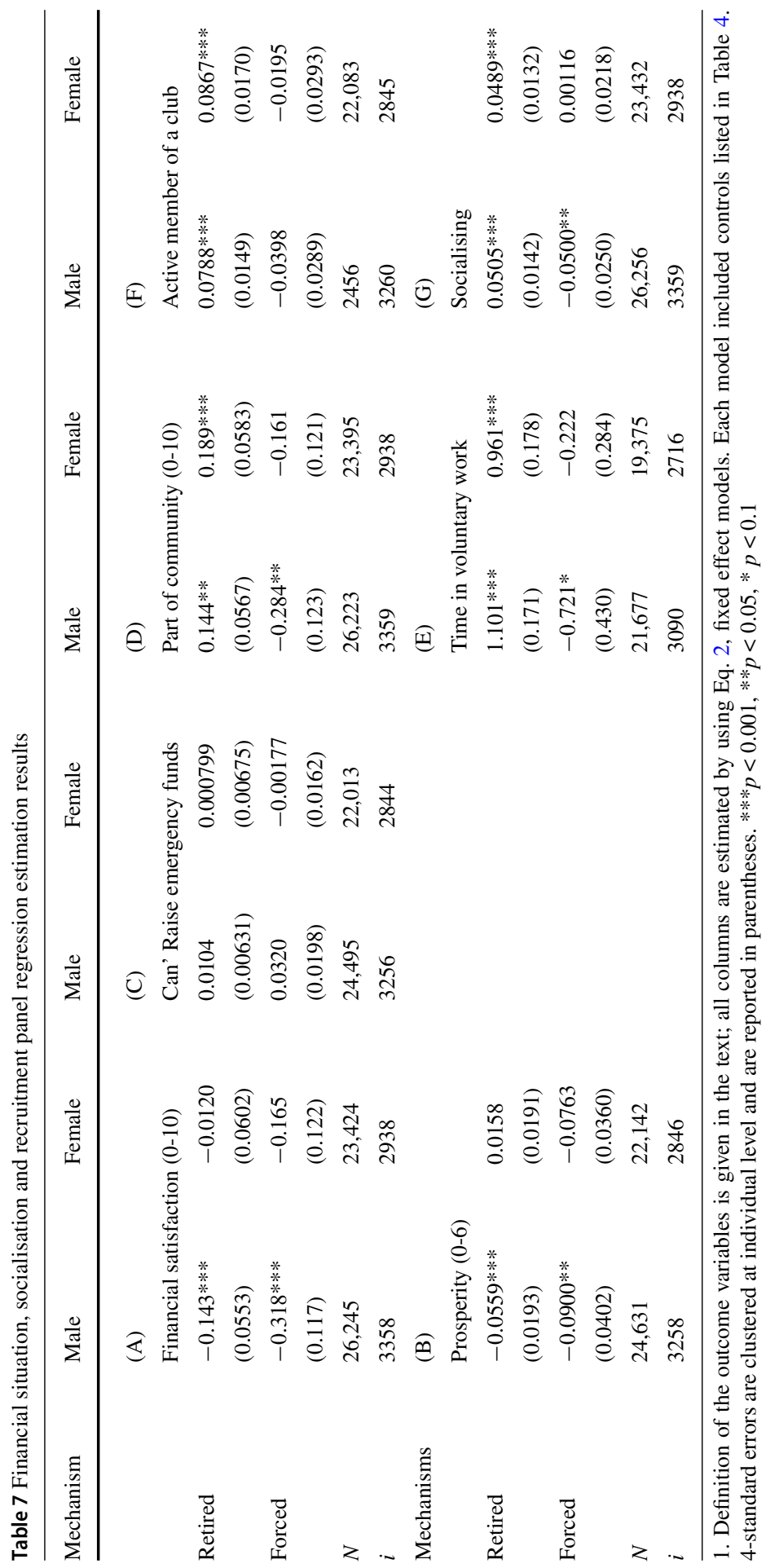


Panels A and B of Table 7 examine the perceived financial situation for males and females, respectively. We find a negative and significant association between involuntary retirement and financial well-being. Panel $\mathrm{C}$ investigates financial hardship by examining the ability of individuals to raise emergency funds. The results show no significant association for men and women. In panels D, E, F and G, we examine outcomes related to the social interaction of individuals. We check individual's satisfaction with being part of the community, whether they are engaged in voluntary work or are an active member of a local club. These measures indicate participation in particular social activities, though they are imperfect as they do not capture the quality or intensity of the social engagements. A further caveat is that the results may reflect reverse causality between retirement, life satisfaction and these outcomes. Bearing these in mind, we observe that time spent in volunteer work increases with retirement per se; however, involuntary retirement has a negative impact on volunteering for men. Similarly, we observe an increase in satisfaction with belonging to a local community, but this effect is significantly smaller for male involuntary retirees (see panel D). Further, we also examine the frequency with which individuals get together socially with friends/relatives (panel G). We generate a binary variable indicating socialising frequency that equals one if the respondent gets together socially with their friends/relatives more than once per month and zero otherwise. The results again show a positive change in social activities by voluntary retirees and no change for male involuntary retirees. These results suggest that, aside from financial consequences, individuals' social participation and their perception of social exclusion are related to the negative effects of involuntary retirement. These findings echo the literature examining the impact of unemployment on social participation. Kunze and Suppa (2017) and Pohlan (2019) show that experiencing unemployment is associated with the stigma of lower social recognition and acceptance, inducing people to withdraw from social activities. Involuntary retirement might carry a similar stigma effect, which affects social participation and in turn have a negative impact on the life satisfaction. Overall, these findings indicate that differential impacts of retirement circumstances can in part be attributed to changes in financial security and social activities of elderly individuals.

\subsection{Cross-Partner Effects of Retirement on Life Satisfaction}

It is well documented that spouses coordinate their retirement decisions (Hurd 1990; Gustman and Steinmeier 1994; Blau 1998). More recent studies based on ex post evaluations of pension reforms provide further evidence that one individual's retirement incentives have a significant effect on their partner's labour force decisions (see Atalay et al. 2019). A related strand of the literature examines the cross-partner health effects of retirement. ${ }^{8}$ Szinovacz and Davey (2004) show that spousal employment affects an individual's post-retirement depressive symptoms in the USA. They show that the beneficial effect of a wife's retirement is related to the enjoyment of joint leisure activities. More recently, several studies use pension eligibility rules to assess the effects

\footnotetext{
8 Kunze and Suppa (2020) show that unemployment of one spouse has a strong negative effect on public social activities of indirectly affected spouses.
} 
of spousal retirement on health outcome. Muller and Shaikh (2018) and Bertoni and Brunello (2017) find that a husband's retirement has a negative effect on his wife's subjective health. On the other hand, Atalay and Zhu (2018) show that spousal retirement has a beneficial effect on the mental health of older men. Collectively, these studies demonstrate that one partner's retirement has a significant impact on the other partner's labour supply and health. Therefore, ignoring within-family spillover effects may lead to an incomplete assessment of the overall impact of program reforms.

While most research has focused on the SWB consequences of one's own retirement, it is reasonable to expect that retirement may affect the well-being of other family members through externalities related to sharing the same residence, having common income and being exposed to similar stressors. One spouse's retirement may affect the well-being of the other spouse due to changes in financial circumstances and non-monetary considerations, such as changes in the amount of time spent together and participating in social activities (Luhmann et al. 2014). The literature on retirement and well-being has hitherto not considered within-couple subjective well-being externalities. This section addresses this void by investigating how one spouse's retirement causally affects the subjective well-being of their partner. Further, the richness of our data enable an exploration of the potential mechanism through which a causal effect may operate.

For this part of the analysis, we restrict our sample to couples in which both partners are aged between 50 and 75 and their age difference is ten years or less. We further restrict our sample to couples who did not experience family formation or dissolution in the prior 3 years. To describe the cross-sectional variation in life satisfaction according to a partners' retirement, we implement a two-step procedure. First, we separately regress life satisfaction on a set of controls which include own and partner's age in quadratic form, schooling, health, state of residence and survey year dummy variables. We then run a local kernel polynomial regression of the residuals from these regressions on the distance from the partner's retirement date. Appendix Fig. A2 has four panels; panel (A) shows how a wife's retirement affects the life satisfaction of her working husband; panel (B) presents the impact of a wife's retirement on her retired husbands; panel (C) illustrates the impact of a husband's retirement on the life satisfaction of his working wife; and finally, panel (D) presents the impact of a husband's retirement on his retired wife. From this figure, we observe that there is a discontinuity associated with a wife's retirement for husbands who are already retired. The evidence in panel (B) suggests that retired husbands are positively impacted by their wife's retirement. In contrast, panel (C) shows that the life satisfaction of working women is negatively affected by their husbands' retirement. This descriptive evidence suggests an asymmetric impact of retirement spillover effects on life satisfaction within the family. Part of these observed cross-sectional differences may be due to the unobservable differences across different types of couples. Our econometric specification therefore permits individual differences in the origin of the SWB scale and relies on within-person variation. 


\subsubsection{Empirical Approach}

The empirical analysis of the effect of retirement on partner's life satisfaction is based on the fixed effect regression model as applied in analysing own retirement. The specification is given by:

$$
\begin{gathered}
S W B_{i t}=\delta_{1} \text { Retired }_{i t}^{p}+\delta_{2} \text { Forced }_{i t}^{p}+\delta x_{i t}+\delta^{p} x_{i t}^{p}+\alpha_{i}+\gamma_{t}+e_{i t} i=1, \ldots, N \\
t=1, \ldots, T
\end{gathered}
$$

where the super script "p" represents the partner. The definition of the control variables and fixed effects is analogous to (2) although the individual effect $\alpha_{i}$ here corresponds to a couple-specific fixed effects. We estimate (4) with and without the forced retirement indicator. With the exclusion of the forced retirement variables, the model specification is the counterpart of (1).

There are two important points to note. First, neither of our specifications include own retirement status as a control variable. It is well documented that spouses coordinate their retirement decisions (Gustman and Steinmeier 2000). More recent studies of pension reforms demonstrate that one individual's retirement incentives have a significant effect their partner's retirement decision (see Atalay et al. 2019). Hence, a person's labour force status is correlated with their partner's labour force participation. The inclusion of an individual's own retirement that is itself affected by the regressor of interest (partner's retirement) in the estimation represents what Angrist and Pischke (2009) refer to as a "bad control". To avoid this problem, we divide our sample into two groups: (a) individuals retired at the time of the survey and (b) individuals who are in the labour force at the time of the survey. A further issue for the specification is that current household income may be endogenous to partner's retirement status. For this reason, we control for non-labour household income which is plausibly exogenous.

\subsubsection{Results and Discussion}

Table 8 presents four panels of results. Panels A and B examine the impact of a wife's retirement on the life satisfaction of her husband, by husband's labour force status. Panels C and D presents the effect of a husband's retirement on his wife's life satisfaction, according to the wife's labour force status. All estimations include control variables though for brevity only the coefficients of most interest are reported. The first column of each panel shows an insignificant association between an individual's life satisfaction while working and the retirement of their partner. When retired, only husbands experience a significant change in life satisfaction with the retirement of their partner, and the change is positive (panel B).

The literature on retirement highlights that whether the transition to retirement is gradual or abrupt is likely to influence the preparedness (for example, through financial planning) of households and hence may have an immediate effect on SWB with retirement and the development of a post-retirement lifestyle. The psychology literature has found that perceived control is strongly related to retirement adjustment (van Solinge and Henkens 2005). In an influential study, Bonsang and Klein (2012) 
Table 8 Cross-partner effects

\begin{tabular}{|c|c|c|c|c|}
\hline & \multicolumn{2}{|l|}{ Panel A } & \multicolumn{2}{|l|}{ Panel B } \\
\hline & $\begin{array}{l}\text { Working } \\
\text { (1) }\end{array}$ & (2) & $\begin{array}{l}\text { Retired } \\
\text { (1) }\end{array}$ & (2) \\
\hline & \multicolumn{4}{|c|}{ Life Satisfaction of Husbands } \\
\hline Wife Retired & $\begin{array}{l}-0.012 \\
(0.031)\end{array}$ & $\begin{array}{l}-0.019 \\
(0.034)\end{array}$ & $\begin{array}{l}0.108 * \\
(0.064)\end{array}$ & $\begin{array}{l}0.083 \\
(0.064)\end{array}$ \\
\hline Wife Forced Retirement & & $\begin{array}{l}0.030 \\
(0.071)\end{array}$ & & $\begin{array}{l}0.096 \\
(0.174)\end{array}$ \\
\hline Observations & 11,634 & 11,634 & 8262 & 8262 \\
\hline \multirow[t]{4}{*}{ Number of Couples } & 2076 & 2076 & 1579 & 1579 \\
\hline & Panel C & & Panel D & \\
\hline & \multicolumn{4}{|c|}{ Life Satisfaction of Wives } \\
\hline & (1) & (2) & (1) & (2) \\
\hline Husband Retired & 0.054 & $0.138 * * *$ & -0.004 & 0.011 \\
\hline & $(0.047)$ & $(0.053)$ & $(0.045)$ & $(0.051)$ \\
\hline \multirow[t]{2}{*}{ Husband Forced Retirement } & & $-0.302 * * *$ & & -0.057 \\
\hline & & $(0.099)$ & & $(0.106)$ \\
\hline Observations & 9728 & 9728 & 9255 & 9315 \\
\hline Number of Couples & 1813 & 1813 & 1671 & 1678 \\
\hline Estimator & $\mathrm{FE}$ & $\mathrm{FE}$ & $\mathrm{FE}$ & FE \\
\hline Controls & $\mathrm{Y}$ & $\mathrm{Y}$ & $\mathrm{Y}$ & $\mathrm{Y}$ \\
\hline Individual and Year Fixed Effects & $\mathrm{Y}$ & $\mathrm{Y}$ & $\mathrm{Y}$ & $\mathrm{Y}$ \\
\hline
\end{tabular}

find that the average effect of voluntary retirement on own life satisfaction is negligible, while involuntary retirement has strong negative effects, which they attribute to decline in satisfaction with income. Involuntary retirement is an unexpected shock to individual and household resources. Our second model distinguishes the effects of a partner's voluntary versus involuntary retirement on own SWB.

The addition of the control for partner's involuntary retirement alters the results for the subsample of working wives, as shown in panel C. For working women, when their husband voluntarily retires on average there is a 0.138 -point increase in the life satisfaction. This is the direct effect of husband's voluntary retirement on SWB and is conditional on observable characteristics such as age, non-labour income and self-assessed health status included in the specification.

For the group of working wives, we observe that involuntary retirement of the husband significantly reduces her life satisfaction. In panel $\mathrm{C}$, the estimated net effect of the involuntary retirement of the husband on her SWB is negative, statistically and economically significant $(0.138-0.302=-0.164)$. In contrast, the results in panels A and B show that the forced retirement of a wife did not significantly impact husband's life satisfaction. Together, the results reveal an asymmetry of the cross-partner effects of retirement and especially forced retirement on an individual's life satisfaction. The 
most important within-family spillover effect was experienced by working wives who experience a marked decline in SWB when their partner is forced to retire. ${ }^{9}$

We also explore the potential mechanisms through which a partner's retirement impacts life satisfaction. A partner's retirement can create intra-household spillover effects through at least three mechanisms. First, the partner's retirement directly affects the household budget, which can reduce resources available for each family member. This income effect is well studied in the economics literature. It is important to note that our results are obtained after controlling non-labour income. There may be associated psychological cost of involuntary retirement borne by partners' concerns over future finances. Our data allow us to check this possibility using subjective financial wellbeing questions. Second, retirement is an important life-changing event that may be particularly stressful for retirees and those around them. Stress spillover has been well documented by researchers investigating a variety of life events and has been shown to negatively impact a partner's life satisfaction and marriage quality. Indeed, stress has been found to impact marriage in several ways; stressors external to marriage have been associated with less satisfying spousal interactions (Repetti 1989), more negative attributions regarding spouse behaviour (Neff and Karney 2004) and marital discord more generally (Karney et al. 2005). Involuntary retirement may be a particular stressor that can affect relationship quality and in turn the life satisfaction of a partner. We examined this possibility using a survey question that specifically asks respondents to indicate their satisfaction with their relationship with their partner (using a rating scale of 0-10). Third, studies show that an individual's retirement can influence the time allocation of their spouse (Bonsang and Van Soest 2020; Atalay et al. 2020). These studies show that an individual tends to change the time they allocate to household errands and work when their partner exits the work force. These changes may increase or decrease their socialising activities. We examine these possibilities in two ways. We use a subjective question that measures respondents' satisfaction with leisure time (0-10). We also examine information on the frequency with which respondents get together socially with friends and relatives. We generate a binary variable indicating social engagement frequency that equals one if the individual interacts socially with their friends and relatives more than once per month and is zero otherwise.

It is important to recognise that the role of these different mechanisms may vary by gender and by work status of the partner. For example, Atalay et al. (2020) show that a husband's retirement has a smaller impact on his wife's time allocation, as wives already spend substantial time on home production activities. Feld (1981) shows that social network size is greater for women than men, which suggests that partner retirement might have heterogeneous effects on personal networks by gender. To examine these mechanisms, we use the fixed effect model (2) with these four different outcome variables. The estimates represent the average within-person change in satisfaction with (a) finances, (b) relationship, (c) leisure and (d) frequency of socialising activities with the partner's transition from employment to retirement, conditional on the other observed covariates.

\footnotetext{
9 We also used FE-IV to address potential endogeneity of partner's retirement, our results show that own retirement increases partner's SWB around 0.3 to 0.6 points, and it is marginally statistically significant $(p$-value $<0.1)$
} 
We observe that a wife's voluntary retirement has a positive impact on her working husband's financial satisfaction. This is consistent with studies that show increases in home production associated with a wife's retirement, such as Aguiar and Hurst (2007). We also see that a wife's voluntary retirement positively affects the social activities of retired husbands (while involuntary retirement is associated with not change in social engagements). A comparable effect on social engagements is found for retired wives when their husband retired. Finally, we observe that leisure satisfaction of a working wife increases with the voluntary retirement of his husband. Overall, these results reinforce the main findings presented in Table 8 . Voluntary retirement has positive effects via complementary leisure and social interaction, whereas involuntary retirement negatively impacts finances, socialising activities and marital quality and satisfaction.

\section{Conclusion}

It is found that the majority of individuals who retire according to their plans do successfully smooth their welfare across this important life cycle phase. Indeed, these individuals on average experience a significant gain in SWB on retirement, which may reflect an easing of liquidity constraints and resolution of uncertainty. Further, based on the FE-IV estimator, individuals who delay their retirement due to changes in social security rules are found to experience a substantial welfare gain when they make the transition from employment to retirement. In contrast, the significant minority of men and women who are forced to retire unexpectedly early do not experience a change in SWB on retirement. There is also evidence of partial hedonic adaptation to retirement for voluntary retirees.

Overall, voluntary retirement is found to be associated with significant improvements in SWB for both women and men. Our analysis suggests that in addition to financial changes, individuals' social participation and time allocation are positively associated with their retirement when they voluntarily retire. Our findings based on SWB measures, which provides a broad metric for assessing welfare, complements and extends studies based on more traditional measures such as expenditure behaviour at the time of retirement. We do find important heterogeneity in the effects of retirement on well-being, especially between voluntary and forced retirement. The latter group experiences a major shock, such as a significant health event, which precipitates an unexpected and early exit from employment into retirement. Moreover, the negative impact of involuntary retirement is greatest for individuals from disadvantaged backgrounds. In terms of lessons for appropriate policy responses, targeting assistance to individuals who are not able to retire as planned may be more effective in promoting welfare gains than a general policy affecting all households. In addition, tailored support services such as assistance with financial management or community engagement activities depending on individual needs are likely to have greatest impact on sustaining well-being into retirement.

Our results also highlight important asymmetries in the effects of an individual's retirement on their partner's life satisfaction. These asymmetries are associated with both retirement circumstances and the gender and labour force status of the partner. 
We find that a husband's involuntary retirement has a negative impact on a wife who is in the work force. This finding is consistent with the research that examines the health spillover effects of retirement (Muller and Shaikh, 2018; Bertoni and Brunello, 2017). We show that the partner's social engagement and financial satisfaction are influenced by involuntary retirement of their spouse. These results highlight that effective public policy programs aimed at mitigating the negative consequences of unanticipated early retirement should adopt a family perspective.

Supplementary Information The online version contains supplementary material available at https://doi. org/10.1007/s00181-022-02213-9.

Acknowledgements This paper uses unit record data from the Household, Income and Labour Dynamics in Australia (HILDA) Survey. The HILDA Project was initiated and is funded by the Australian Government Department of Social Services (DSS) and is managed by the Melbourne Institute of Applied Economic and Social Research (Melbourne Institute). The findings and views reported in this paper, however, are those of the authors and should not be attributed to either DSS or the Melbourne Institute. We thank Andrew Clark, Woo-Yung Kim and participants at the KLI Conference on Work and Happiness for helpful comments on a previous draft. Funding from the Australian Research Council Grant DP150101718 is gratefully acknowledged.

Funding Open Access funding enabled and organized by CAUL and its Member Institutions.

Open Access This article is licensed under a Creative Commons Attribution 4.0 International License, which permits use, sharing, adaptation, distribution and reproduction in any medium or format, as long as you give appropriate credit to the original author(s) and the source, provide a link to the Creative Commons licence, and indicate if changes were made. The images or other third party material in this article are included in the article's Creative Commons licence, unless indicated otherwise in a credit line to the material. If material is not included in the article's Creative Commons licence and your intended use is not permitted by statutory regulation or exceeds the permitted use, you will need to obtain permission directly from the copyright holder. To view a copy of this licence, visit http://creativecommons.org/licenses/ by/4.0\%.

\section{References}

Abadie A (2003) Semiparametric instrumental variable estimation of treatment response models. J Econ 113(2):231-263

Aguiar M, Hurst E (2005) Consumption versus expenditure. J Polit Econ 113:919-948

Aguiar M, Hurst E (2007) Life-cycle prices and production. Am Econ Rev 97(5):1533-1559

Angrist DJ, Pischke JS (2009) Mostly harmless econometrics: an empiricist's companion. Princeton University Press

Alan S, Atalay K, Crossley TF (2008) The adequacy of retirement savings: subjective survey reports by retired Canadians. Can Public Policy 34(Supplement):95-118

Ardito C, Leombruni R, Blane D, d'Errico A (2020) To work or not to work? the effect of higher pension age on cardiovascular health. Ind Relat. https://doi.org/10.1111/irel.12257

Atalay K, Barrett G (2015) The impact of age pension eligibility age on retirement and program dependence: evidence from an Australian experiment. Rev Econ Stat 97(1):71-87

Atalay K, Zhu R (2018) The effect of a wife's retirement on her husband's mental health. Appl Econ 50:4606-4616

Atalay K, Barrett G, Siminski P (2019) Pension incentives and the joint retirement of couples: evidence from two natural experiments. J Popul Econ 32(3):735-767

Atalay K, Barrett G, Staneva A (2020) The effect of retirement on home production: evidence from Australia. Rev Econ Household 18:117-139 
Attanasio O (1999) Consumption. In: Taylor JB, Woodford M (eds) Handbook of macroeconomics. 1B, North-Holland, Amsterdam, pp 741-812

Banks J, Blundell R, Tanner S (1998) Is there a retirement savings puzzle? Am Econ Rev 88(4):769-788

Baker M, Gruber J, Milligan KS (2009) Retirement income security and well-being in Canada. NBER Working Paper 14667

Barrett GF, Brzozowski M (2012) Food expenditure and involuntary retirement: resolving the retirement consumption puzzle. Am J Agr Econ 94(4):945-955

Barrett GF, Kecmanovic M (2013) Changes in subjective well-being with retirement: assessing savings adequacy. Appl Econ 45(35):4883-4893

Battistin E, Brugiavini A, Rettore E, Weber G (2009) The retirement consumption puzzle: evidence from a regression discontinuity approach. Am Econ Rev 99(5):2209-2226

Bender KA (2004) The well-being of retirees: evidence using subjective data. CRR Working Paper No. 200424, Available at SSRN: https://ssrn.com/abstract=1147678 or https://doi.org/10.2139/ssrn.1147678

Bernheim D, Skinner J, Weinberg S (2001) What accounts for the variation in retirement wealth among U.S. households? Am Econ Rev 91(4):832-857

Bertoni M, Brunello G (2017) Pappa Ante Portas: the effect of the husband's retirement on the wife's mental health in Japan. Soc Sci Med 175:135-142

Blau DM (1998) Labor force dynamics of married couples. J Law Econ 16(3):595-629

Bonsang E, Adam S, Perelman S (2012) Does retirement affect cognitive functioning? J Health Econ 31:490-501

Bonsang E, Klein T (2012) Retirement and subjective well-being. J Econ Behav Organisation 83:311-329

Bonsang E, Van Soest A (2020) Time devoted to home production and retirement in couples: a panel data analysis, Labour Economics, vol 65C. Elsevier

Borella M, Coda Moscarola F, Rossi M (2014) (Un)expected retirement and the consumption puzzle. Empir Econ 47:733-751

Browning M, Crossley TF (2001) The life-cycle model of consumption and saving. J Econ Perspect 15:3-22

Casanova M (2010) Happy together: a structural model of couples' joint retirement choices." Working paper, Department of Economics UCLA

Charles KK (2004) Is retirement depressing? labour force inactivity and psychological well-being in later life in SW. Polachek (ed), Research in Labour Economics, v.23, Amsterdam

Ciani E (2016) Retirement, pension eligibility and home production. Labour Econ 38:106-120

Clark AE, Diener E, Georgellis Y, Lucas RE (2008) Lags and leads in life satisfaction: a test of the baseline hypothesis. Econ J 118:F222-F243

Clark AE, Fawaz Y (2009) Valuing Jobs via Retirement: European Evidence. National Institute Econ Rev 209:88-103

Clarke P, Marshall VW, Weir D (2012) Unexpected retirement from full time work after age 62: consequences for life satisfaction in older Americans. Eur J Ageing 9:207-219

Casanova M (2010) Happy together: a structural model of couples' joint retirement choices Working paper, Department of Economics UCLA

Coile C (2004) Retirement incentives and couples' retirement decisions Topics in Economic Analysis and Policy 4 Article 17

Coile C (2015) Economic determinants of workers' retirement decisions. J Econ Surv 29(4):830-853

Dayaram K, McGuire A (2019) Retirement reforms: occupational strain and health. Ind Relat 58(3):522-542

Di Tella R, MacCulloch R (2006) Some uses of happiness data in economics. J Econ Perspect 20(1):25-46

Diener E, Suh EM, Lucas RE, Smith HL (1999) Subjective well-being: three decades of progress. Psychol Bull 125(2):276-302

Dolan P, Peasgood T, White M (2008) Do we really know what makes us happy? a review of the economic literature on the factors associated with SWB. J Econ Psychol 29(1):94-122

Easterlin RA (2005) Building a better theory of well-being. In: Bruni L, Porta PL (eds) Economics and happiness: framing the analysis. Oxford University Press, New York, pp 29-64

Falba TA, Gallo WT, Sindelar JL (2009) Work expectations, realizations, and depression in older workers. J Ment Health Policy Econ 12:175-186

Feld SL (1981) The focused organization of social ties. Am J Sociol 86:1015-1035

Ferrer-i-Carbonell A, Frijters P (2004) How important is methodology for the estimates of the determinants of happiness? Econ J 114(497):641-659

Frey B, Stutzer A (2002) Happiness and economics: how the economy and institutions affect human wellbeing. Princeton University Press, Princeton 
Graham C, Nikolova M (2015) Bentham or Aristotle in the development process an empirical investigation of capabilities and subjective well-being. World Dev 68:163-179

Gustman AL, Steinmeier TL (1994) Employer provided health insurance and retirement behavior (No. w4307). National Bureau of Economic Research

Gustman AL, Steinmeier TL (2000) Retirement in dual-career families: a structural model. J Labor Econ 18(3):503-545

Gustman AL, Steinmeier TL (2004) Social security, pensions and retirement behaviour within the family. J Appl Economet 19:723-737

Guy Harling KA, Morris L, Manderson JM, Perkins LFB (2020) Age and gender differences in social network composition and social support among older rural South Africans: findings from the HAALSI study. J Gerontol Series B 75(1):148-159

Haider S, Stephens M (2007) Is there a retirement consumption puzzle? evidence using subjective retirement expectations. Rev Econ Stat 89(2):247-264

Hamermesh DS (1984) Life-cycle effects on consumption and retirement. J Labor Econ 2(3):353-370

Hauret L, Williams DR (2017) Cross-national analysis of gender differences in job satisfaction. Ind Relat 56(2):203-235

Horner EM (2014) Subjective well-being and retirement: analysis and policy recommendations. J Happiness Stud 15(1):125-144

Hurd MD (1990) The joint retirement decision of husbands and wives in Issues in the Economics of Aging, Wise, DA (ed) University of Chicago Press: Chicago

Hurd M, Rohwedder S (2003) The retirement consumption puzzle: anticipated and actual declines in retirement spending NBER Working Paper 9586

Imbens GW, Wooldridge JM (2009) Recent developments in the econometrics of program evaluation. J Econ Lit 47(1):5-86

Kahneman D, Krueger AB (2006) Developments in the measurement of subjective well-being. J Econ Perspect 20(1):3-24

Kapteyn A, Lee J and Zamarro G Does retirement induced through social security pension eligibility influence subjective well-being? a cross-country comparison Working Paper No. WP 2013-301, University of Michigan Retirement Research Center (MRRC), Ann Arbor, MI, 2013

Karney B, Story LB, Bradbury TN (2005) Chronic and acute stress among newly- weds. In: Revenson TA, Kayser K, Bodenmann G (eds) Couples coping with stress. American Psychological Association, Washington, DC, pp 13-32

Kunze L, Suppa N (2017) Bowling alone or bowling at all? the effect of unemployment on social participation. J Econ Behav Organ 133:213-235

Kunze L, Suppa N (2020) The effect of unemployment on social participation of spouses: evidence from plant closures in Germany. Empir Econ 58(2):815-833

Luhmann M, Weiss P, Hosoya G, Eid M (2014) Honey, I got fired' a longitudinal dyadic analysis of the effect of unemployment on life satisfaction in couples. J Pers Soc Psychol 107(1):163-180

Machado JAF and Santos Silva JMC (2019) Quantiles via moments, J Econ forthcoming

Marbach M, Hangartner D (2020) Profiling compliers and non-compliers for instrumental variable analysis. Polit Anal 28(3):435-444

Montizaan R, Vendrik M (2014) Misery loves company: exogenous shocks in retirement expectations and social comparison effects on subjective well-being. J Econ Behav Organisation 97:1-26

Muller T, Shaikh M (2018) Your retirement and my health behavior: evidence on retirement externalities from a fuzzy regression discontinuity design. J Health Econ 57:45-59

Neff L, Karney B (2004) How does context affect intimate relationships? linking external stress and cognitive processes within marriage. Pers Soc Psychol Bull 2004(30):134-148

Panis C (2003b) Annuities and retirement satisfaction, RAND Labor and Population Program Working Paper 03-17, DRU-3021

Pohlan L (2019) Unemployment and social exclusion. J Econ Behav Organ 164:273-299

Repetti RL (1989) Effects of daily workload on subsequent behaviors during marital interaction: the roles of social withdrawal and spouse support. J Pers Soc Psychol 57:651-659

Rohwedder S (2006) Self-assessed retirement outcomes: determinants and pathways, Working Paper WP 141, University of Michigan Retirement Research Center

Smith S (2006) The retirement consumption puzzle and involuntary early retirement: evidence from the British household panel survey. Econ J 116(March):C130-C148 
Stock J, Yogo M (2005) Testing for weak instruments in linear IV regression. In: Andrews DWK identification and inference for econometric models. Cambridge University Press, New York, pp 80-108

Szinovacz ME, Davey A (2004) Honeymoons and joint lunches: effects of retirement and spouse's employment on depressive symptoms. J Gerontol 59:233-245

Van Solinge H, Henkens K (2005) Couples' adjustment to retirement: a multi-actor panel study. J Gerontol Series B Psychol Sci Soc Sci 60(1):S11-S20

Zhu R, He X (2015) How does women's life satisfaction respond to retirement? a two-stage analysis. Econ Lett 137:118-122

Publisher's Note Springer Nature remains neutral with regard to jurisdictional claims in published maps and institutional affiliations. 